\title{
On the Need for an Ethical Understanding of Health Care Accountability
}

\begin{abstract}
In Sweden, like in many other Western countries, public health care is challenged by increasing demands for care and by continuing budget deficits. Person-centered care (PCC) has been introduced as a new strategy to ameliorate the perceived fragmentation in care and is expected to decrease treatment time, reduce the need for return visits, as well as to increase patient satisfaction. However, the changing clinical practices in the PCC approach are assumed to require new accountability practices. This paper is primarily an attempt to characterize a notion of ethical accountability, i.e., a type of accountability that takes into account the human relational responsibility, partial incoherence, and power of reflection. On the grounds of this characterization, the paper aims to provide a basis, among other things, for a discussion of the possibilities of identifying and empirically studying the multimodal expressions in communication that are relevant for this type of accountability.
\end{abstract}

After an initial discussion of the debate on the limits of viewing accountability as transparency, we then turn to our methodological approach and introduce a conceptual analysis of accountability. Next, we discuss some additional features of accountability. Finally, we discuss the possibilities of empirically studying the institutionalization of ethically informed accountability within person-centered health care.

Key-words accountability, health care, person-centered care, ethics, linguistic approach, multimodal communication 


\section{Introduction}

The purpose of this paper is to provide a conceptual analysis of accountability and on the basis of this to develop a conceptual model facilitating empirical studies of accountability practices. The model is assumed to be applicable to various contexts, although we focus on person-centered care (PCC) to illustrate the model and to discuss research implications. To test the model in empirical studies is beyond the purpose of this paper.

The Swedish public health care system is governed by the Ministry of Health and Social Affairs and the National Board of Health and Welfare. It is financed primarily by taxes and based on the provision of care by county councils/regions and municipalities. The municipalities are responsible for financing and providing care at nursing homes and other types of housing for older people and mentally impaired patients, while the county councils/regions are responsible for all other types of care.

In Sweden, like in many other countries in the Western world, public health care is challenged by ever increasing demands for care and by continuing budget deficits. In recent decades, several policy initiatives have been taken to enhance the efficiency of Swedish health care providers. The most recent initiative, reinforced by the market rhetoric of empowering the patient, is the introduction of care choice within primary care. This reform gives the patients the right to choose which primary care center from which they want to obtain treatment. By competing for patients and for the money attached to the treatment of those patients, the primary care centers are expected to be encouraged to provide more and better health care. Similar changes have been taking place in other Nordic and European countries. The results, however, have been disappointing both financially and socially (Johansson et al., 2010). 
A report from the Institute of Medicine, "Crossing the Quality Chasm," states that patients often must navigate through a fragmented health care system and adapt to the customs and usual procedures of health care organizations and professionals, rather than receive care designed to focus on an individual's needs, preferences, and values (Committee on Quality of Health Care in America, Institute of Medicine, 2001). PCC has been introduced - in Sweden and elsewhere - as a new strategy to ameliorate the perceived fragmentation in care, and this strategy has shown positive results to date (Ekman et al., 2011). PCC asserts that patients are persons and, for this reason, should not be reduced to their disease alone, but rather that their context, experiences, goals, and wishes should also be taken into account. The intention behind PCC is to adapt treatment and care to each individual by encoding and enacting three organizational routines: 1 . Initiating a partnership with the patient by paying careful attention to the narratives of the patients in order to determine their motivation, resources and goals, 2. Working the partnership by establishing shared decision-making and collaboration with the patient as a person, and 3. Safeguarding the partnership by documenting the patient narrative and the mutually developed health care plan (Ekman et al., 2011). The enactment of these three routines is expected to result in decreased treatment time and a reduced need for return visits, as well as increased patient satisfaction. However, changing clinical practices to a PCC approach is believed to pose a number of challenges given that professionals often believe, without much supporting evidence, that the care they provide is already person-centered. It is for this reason that what is meant by PCC and what the implementation of PCC requires are topics that are receiving increasing interest among researchers today (see Rosemond et al., 2012), particularly with respect to the need for empirical studies. In a systematic literature review of PCC as an intervention in controlled trials, 11 studies were found (Olsson et al, 2012). The studies were conducted in different countries; Sweden (4), USA (2), Finland (2), Canada (1), Australia (1) and the UK (1). In eight out of the 11 studies PCC as an intervention was shown to be successful. Although suggesting that PCC may lead to 
significant improvements, it was concluded that more studies are needed in order to assess the implementation and relevant effects.

In this paper, we will raise accountability issues in relation to PCC. Increasing patient involvement, e.g., by partnership and shared decision-making, raises concerns about who should learn what from mistakes - and how (c.f. Wirt et al., 2006; Ocloo, 2010).We will assume that a person-centered approach to health care, more than any other health care approach, requires ethically informed accountability processes - whether these are demands and responses from patients, care professionals, managers, or politicians. One crucial situation in PCC is the one that occurs between patient and care professionals (normally a nurse and a doctor forming a team), in which the treatment and prognosis are discussed in relation to agreeing on a health care plan. Care issues are very important here. The narrow context of this situation involves accountability processes that take place between the patients/relatives and the health professionals, as well as among the health professionals who are involved in the treatment of the patient, and in addition, accountability processes between the professionals and their managers concerning administrative and financial matters. The wider context further involves accountability processes between managers at different levels and from different administrative units, as well as accountability between managers and politicians. We note that public health care is regulated and supervised through very complex accountability norms, involving medical, administrative, and financial requirements, which may collide (c.f., Hor et al., 2010; Iedema et al., 2006).

Accountability is a dynamic and complex phenomenon and a crucial concept in the understanding of social action. Central to accountability are accounts. In this paper, we will mainly focus on a type of social account, namely, the accounts people give every day to each other about their doings. The accounts given in situations where a person identifies him/herself, or is identified by other people as accountable, are, however, different from 
ordinary accounts, in that people may need to give accounts in delicate situations that are imprinted by doubt and ethical concerns.

Contemporary institutions and societies depend on functioning accountability practices. Citizens, consumers, employees, shareholders etc. need to be able to trust that representatives for public organizations and companies act in the interest of all stakeholders, not giving preference to a minority of them. Effective accountability practices increase the likelihood that the representatives assume responsibility, are held accountable if not and that they are punished if found to have acted irresponsibly. What is called the accountability movement affecting western institutions (c.f. van Woerkum \& Aarts, 2012) stresses the need for more accountability, encompassing an increasing number of professionals.

Today, accountability issues are discussed often, mostly because public officials and managers of large corporations have been found to act in ways which have been harmful to the basic values in society and against the interests of citizens and corporation owners. The response to these problems has been calls for greater accountability, improved auditing, and stronger sanctions for misconduct. The temptation to see increased regulation of accountability as the solution is evident. However there are indications that more rules regulating the work of auditors, rather than leading to greater trust, may lead to a calculative behavior that is more damaging to societal and organizational trust (see e.g. Baldvinsdottir \& Johansson, 2006 and e.g. Laughlin, 2007, who explain reactions to accounting regulation). In line with the more optimistic professionalization literature it could even be argued that statutory and organizational forms of accountability may be detrimental to the quality of work and that a form of individualized internal self-regulation thus is more appropriate (c.f. Evetts, 2013). 
We thus have research pointing to the need for increased accountability (and accounting) and research criticizing such efforts. Drawing on the writings of Foucault (e.g. 1979) the disciplinary power of accounting has been discussed for decades (c.f. Hoskin \& Macve, 1986; Miller \& O’Leary, 1987; Hoskin \& Macve, 1994; Colwyn Jones and Dugdale, 2001). Although, Foucault himself did not address accounting or economic processes, the influence of his work on the understanding of these phenomena has been significant, pointing to the fact that accounting and accountability serve the purpose of rendering organizational activities and people transparent, knowable, calculable and manageable: "The perfect disciplinary apparatus would make it possible for a single gaze to see everything constantly. A central point would be both a source of light illuminating everything that must be known, a perfect eye that nothing would escape and a centre towards which all gazes would be turned" (Foucault, 1979, p.173).

According to Roberts (2009), the belief in accountability as transparency is a mistake because it leads people into defensive and self-assertive behaviors that contradict the very basic idea of accountability as an activity which will help people and organizations to learn and improve. To play such a role, those who are engaged in accountability processes have to accept that no one is perfect and should not try to appear to be perfect themselves. Roberts suggests a more reflective form of accountability, in which feedback is important. We cannot be aware of the consequences of all our actions, thus we need feedback from others. In this sense, accountability is an interdependent endeavor, assuming responsibility for one another. In line with this idea, accountability needs to become a project of reciprocal understanding between those involved, concerning their respective responsibilities, and not asking too much from the other party. Roberts concludes by proposing "a more provisional form of accountability; less 
certain of the truth, and the relevance or adequacy of existing standards of judgement, and more conscious of my own and others' vulnerability" (2009:967).

Accountability as a controlling device is found to have its limits because of the "accountable self as an opaque, exposed, and mediated self” (Messner, 2009). As human beings, we sometimes do not know exactly why we take the actions we do, which makes it impossible to explain what we have done - even to ourselves. If we are then exposed to demands for accountability from other people with little or no understanding of our problems, it may cause cognitive stress obstructing our work, although the intention behind the demands may be to help improve our work (Freeman et al., 2009). Another limit is the problems caused by ongoing needs to justify one's actions. If there is no trust in an environment, we may become paralyzed, not daring to act, and obsessed with covering up mistakes. The third limit of accountability mentioned by Messner (2009) is the fact that there are often multiple and conflicting demands for accountability, both at the top and at the lower levels of an organization. Accountability may therefore place a burden "on the accountable self who is expected to provide a convincing account even in situations where this is extremely difficult or even impossible” (Messner, 2009: 918).

Acknowledgement of these limits, which reduces the burden and fear of being found imperfect, is assumed to lead to a more practical and realistic accountability practice. What is needed is an 'intelligent' accountability that acknowledges the power of reflection, the need for feedback, peoples' partial incoherence, and their relational responsibilities - i.e., an ethically informed accountability (Roberts, 2009). The frame of reference on ethics adopted in this paper owes much to Roberts $(2009 ; 2001)$ and his interpretation of Levinas (1991). This implies an accountability based on reflection-in-action (c.f. Keevers \& Treleaven, 2011) as well as reflection-on-action. While there is some research on the latter, 
less is known about the former (Jordan, Messner, \& Becker, 2009:466). For an understanding of this concept in a health care context, we believe that communication, especially its multimodal features, might be relevant. Accordingly, we suggest studying multimodal communication (i.e., facial expressions, gestures, body posture, vocal verbal expressions, and touch) in accountability processes. The following quote (Oudshoorn, 2009:395) explains why multimodal communication is important for nurses' interpretation of the accounts given by patients:

'Although auditory resources thus play a role in the evaluation of patients' accounts of their illness, nurses prioritise visual cues. According to nurses, patients may often tell them they are doing fine, also when they have swollen feet or breathing problems:

Sometimes patients don't tell you what is wrong, simply because they don't want to be ill ... In the policlinic I can see them. Maybe very simple, but this is how it is (Interview heart-failure nurse C).

Visual resources are considered as even more important than the objective measurement of blood pressure:

Look, a blood pressure tells you a lot, but not everything. Someone can have a nice blood pressure but look very miserable. A blood pressure does not reveal that. Therefore, you want to keep seeing your patients. Eyes can always tell you more than ...(Interview heart-failure nurse B). 
Visual cues are thus valued more than other resources, particularly in those cases in which nurses detect contradictions with the measurements of bodily indicators or the accounts of patients (Interview heart-failure nurses B and C).'

The quotes indicate that nurses, when interpreting patients' accounts, also interpret patients' facial expressions, body postures, etc., and if found relevant, those features are included and sometimes given priority over the vocal verbal accounts. This means that the account of the patients is being interpreted multimodally and, as a consequence, also makes the outcome of the treatment dependent on this multimodal communication. To a large extent, this concept also holds for communication between health professionals.

Against this background, the main purpose of this paper is to provide a conceptual analysis and a conceptual model of accountability. Building on the analysis, we discuss the possibilities of empirically studying multimodal expressions relevant for an ethically informed accountability in the context of PCC. In the following section, we present our method and then provide a conceptual analysis of accountability. Next, we identify some critical features of accountability as a morally significant practice. Finally, we discuss the implications for empirical studies of accountability in the context of PCC.

\section{Method}

The paper is primarily an attempt to develop a concept of accountability, which makes room for a reflective and ethically informed consideration of different cognitive and other factors that can influence practices and social activities where accountability is a central concern. In developing the conceptual analysis (and model) of accountability, we have relied on a combination of literature review and linguistically informed conceptual analysis. In line with 
this approach, we have analyzed the "meaning potential" (i.e., the possible meanings or uses of a word) of the word accountable to capture the various meanings and uses the words account, accountable and accountability can have.

To be more specific, we have considered (i) the etymology of the word accountability, (ii) its morphological analysis, (iii) definitions given for accountability and its constituents accountable and account, (iv) relevant parts of the semantic field of accountable and account, and finally (v) aspects of how the word is used, as reflected in an analysis of its semantic roles.

Combining a literature review with an analysis of the word accountability and its constituents, in addition to considering some of the synonyms in their semantic field, allows us to sketch a model of what we hope is a contextually sensitive and ethically informed notion of accountability.

\section{Conceptual analysis of accountability}

\section{Meaning potential of accountability}

One possible approach to studying the concept of "accountability" is to study the meaning potential of the word accountability, cf. Allwood (2003) and Allwood \& Gunnarsson (2003). The meaning potential of a word is the collection of its possible meanings or uses. A description of a meaning potential usually involves a consideration of its history (etymology), a consideration of its morphological structure, a definition and an analysis of some or all of its uses. Below, we first describe the morphological structure of word accountability in the form of a diagram. Then, we consider its etymology and definition. 
Insert Diagram 1 about here.

The diagram shows that the root of the word accountability is the verb/noun account-, to which in a second step the suffix -able (meaning "possibility for" or "potential") can be added, yielding account-able (the property of being possible to account for or the property of being held responsible for giving an account). Other possibilities are -ing and -ant, giving accounting and accountant. In a third step, the suffixes -ly, -ity, and -ness can be added, yielding account-ab-ly, account-abil-ity, and account-able-ness (the reified property of being possible to account for), where account-abil-ity can be used to holistically refer to what is involved in being possible to account for. Next, we consider the etymology of the root account and, by extension, the derived forms accountable and accountability.

\section{Etymology}

Accountability from late Latin accomptare (to account)

From $a+$ comptare (to calculate) from putare (to reckon)

Verb - to account (for)

Noun -> an account (resultative reification of accounting action)

The morphological analysis and etymological description, together, suggest that the action of accounting is basic for the notion of "accountability". The noun account is secondary, referring to a result of this activity. The derived forms account-able and account-abil-ity are both based on the activity, meaning "possible to account for" and "reification of the property of being possible to account for". We can now turn to a definition of accountability that we will provide by first giving definitions of account and accountable. The definitions are 
followed by a semantic field that lists some terms closely related and partly synonymous with the defined terms.

Definitions

Definition of account (as a verb):

Account for $=$ report , describe in a comprehensible and acceptable way

Semantic field: explain or justify

Definition of accountable:

Accountable $=$ liable (obligation/expectation) to (be able to) account for one's observations or other actions, i.e., to report, describe on one's observations or actions in a comprehensible and acceptable way

Semantic field: responsible, answerable, obliged, liable, amenable, obligated, chargeable

Note here that being accountable does not strictly imply being responsible and that being responsible does not imply being accountable. We can be accountable without being responsible, and we can be responsible without being accountable. The reason for this is that responsibility implies intentional control. We can only be responsible for actions we can (intentionally) control. If we have no control, we cannot be responsible. We could, however, be accountable for something we have had no possibility of controlling but only of observing (e.g., a watchman reporting the approach of the enemy).

However, being accountable for $X$ is often most relevant if you also are responsible (for $X$ ). This notion is socially reinforced by the fact that positive and negative sanctions are usually connected with actions and results of actions. If you are responsible (for $X$ ), such sanctions 
would then be relevant both with regard to the actions for which you were responsible and with regard to your account of these actions, often combining consideration of both. To be held accountable is, therefore, a socially important notion that we can define as follows:

To be held accountable $=$ to be under expectation, obligation (to be able) (w. r. t. norms, conventions, purpose, causal regularities) to give an acceptable and comprehensible (w.r. t. norms, conventions, purpose, causal regularities) report (account) of performed actions. We can see here how the notion of "accountability" brings in, and is often based on, the consideration of several other basic social relations, norms, conventions, purposes, and causal regularities. The fact that it is not always possible to act in a way such that your actions are describable in a comprehensible and acceptable way according to relevant norms, conventions, purposes, and causal regularities means that giving an account often necessitates including explanations, justifications, apologies, and excuses in your account. Based on the definition of accountable, we are now ready to give a definition of accountability.

Definition of Accountability:

Accountability $=$ reification of the ability to give an account, often combined with expectations/assumptions concerning account giving, encompassing reporting, and explaining actions.

Semantic field of accountability: answerability, blameworthiness, liability, responsibility

In line with what is stated above, we can now note that an awareness of accountability and accountableness often leads to a need for excuses, justifications, rationalizations, explanations or apologies. 
Finally, we turn to an analysis of some of the uses of the notion of "accountability" and the actions and semantic roles it is based on.

Actions and Semantic Role analysis related to accountability

The phenomenon of "accountability" can involve at least three actions, each with its own potential set of semantic roles. The sematic roles are the relational terms (arguments) of the relations involved in an action, usually the entities involved, to accomplish the action. Examples are the roles of the agent, object or instrument of the action. Each of the three actions we have selected as relevant for accountability can potentially involve its own set of semantic roles:

Action 1: Person $\mathrm{X}$ performs/observes action 1 (with all semantic roles relevant to action 1) Action 2: Person $\mathrm{X}$ accounts for action 1 to person $\mathrm{Z}$

Action 3: Person $\mathrm{X}$ is held accountable by person $\mathrm{W}$ (who can be person $\mathrm{Z}$ ).

$\mathrm{X}, \mathrm{Z}$ and $\mathrm{W}$ are above given as persons but could possibly under some circumstances be animals or computer programs. The roles involved in the three actions are as follows:

1. - Action accounted for (involving the roles; agent, action, object, purpose, patient, result, instrument, time, place)

2. - Accounting (involving the roles; agent, action, object, purpose, patient, result, instrument, time, place)

3. - Holding accountable (involving the roles; agent, action, object, purpose, patient, result, instrument, time, place)

The actions and the roles related to actions 2 and 3 can also be presented in the form of a table where action1 is presupposed. 
Insert Table 1 about here.

Using the semantic role analysis, we can formulate a number of questions and issues. These questions and issues can be the point of departure for empirical investigations throwing light on the nature of accountability processes in different social activities.

Questions generated by the semantic role analysis
Who (agent) accounts
for what (object) to whom (patient)
gives accounts
of what to whom
is accountable
for what to whom
is held accountable
for what to whom
by whom (benefactor)

for what purpose,

in what activity,

with what results,

with what instruments,

at what time and place?

These questions can all be empirically investigated in actually occurring social activities and, in this way, help us understand more deeply how accountability and demands for acceptable accounts help to structure the activity.

As a final part of our analysis, we provide some terminological suggestions that will be used throughout the remainder of the paper. 
Account giver - person(s) who give an account

Account topic - topic of the account

Account recipient - person(s) receiving the account

Account obliger - person(s) demanding the account

Account time and/or place - the time and/or place of the account,

Account activity - the social activity the account is a part of

Account purpose, result, instrument - the purpose, result, instrument of the account.

Based on this conceptual analysis, we will now discuss some additional features of accountability.

\section{Accountability as a morally significant practice}

Bovens (2007) distinguishes between four types of accountability associated with four types of "agents" (account givers): corporate, hierarchical, collective, and individual accountability. In this paper, our focus is on individual accountability because of our interest in the human power of reflection, peoples' partial incoherence, and their relational responsibilities. Another categorization of accountability types is dependent on the type of social activity (forum) and the recipients of the accounts, the persons to whom the accounts are to be given. In public and organizational settings, accountability implies a formal obligation to render accounts on a regular basis which is normally not the case between family members or friends (see e.g., Walker \& Llewellyn, 2000). Bovens describes five different types of accountability confronting public organizations and officials: political, legal, administrative, professional, and social accountability. By social accountability Bovens means the accountability of "public agencies, on the one hand, and clients, citizens, and civil society, on the other hand" (p. 457). We will mainly focus on administrative and professional accountability because this 
involves significant processes in the day-to-day operations of organizations. Whereas administrative accountability has to do with managing and controlling activities, professional accountability implies relationships with professional bodies that use codes and standards to evaluate acceptable practices.

\section{Accountability as a social relation}

As we have mentioned, sometimes "to demand an account from someone is to ask this person to enact discursively the responsibility for her behavior" (Messner, 2009: 920). Even if this is not always the case, it very often is. This claim can be understood by looking at two dimensions of accountability: an external (in relation to other people) and an internal dimension (in relation to oneself) (Mulgan, 2000). The external dimension refers to the expectation from members of the community that all actors will behave appropriately. It involves the evaluation of actions taken (or not taken) by an actor and the imposition of sanctions (Mulgan, 2000: 561). In legal contexts, three elements are considered prerequisites for a person to qualify as accountable, i.e., to know what you are doing, to know what is considered as right and wrong to do, and to be able to control one's actions (c.f. Radovic, S., 2009). The internal dimension refers to the actions that an actor takes to meet those expectations and can involve the practice of responsibility because an actor often makes ethically relevant choices in deciding about her/his actions. These ethically relevant choices among other things reflect the actor's internalized sense of accountability - ethics and professional/personal responsibility (Messner, 2009; Mulgan, 2000; Sinclair, 1995), emotions, and values (Sinclair, 1995). The distinction between guilt and shame can perhaps be used here to illuminate the difference between the internal and the external requirements. People may be considered guilty by other people (external) and thus feel shame without really feeling guilty 
themselves. It is also possible for people to have a guilty conscience and to feel guilt without any guilt allegations from others (internal).

Viewing accountability as a social relation can include noticing that some elements are constitutively created (Bovens, 2007:452, see Figure 1). These elements are needed for a social relation to qualify as a practice of accountability, focusing on the communication between the account giver and the account recipient. However, what happens inside the account giver, i.e., the reflected activities when exposed to demands from the account recipient, is not given a central role. "Intra-personal accountability involves a reflected relationship with the self in which I judge myself against an ideal that, through identification, I take as my standard of what I should, and should not be and do" (Roberts, 2009:961). This means that accountability is both a relationship with other people and an internal relationship with oneself, where some persons may experience clashes between external scrutiny and internal discretion in accountability processes (Mulgan, 2000). Care professionals and managers for example may find it stressful having either lower or higher standards themselves compared to the standards of their colleagues (Wikström \& Dellve, 2009). When it comes to patients, it is more a question of how much information they are willing to share with care professionals - and how much information professionals are interested in receiving from the patients (Kukla, 2005, 2007; Potter \& Mueller, 2007).

Insert Figure 1 about here.

\section{Accountability and the human power of reflection}

The concept of "reflexivity," which is related to what we are calling "the power of reflection," has been an important tool in sociological analysis for years, e.g., in relation to making the 
world understandable (Garfinkel, 1984). To Garfinkel, “accountable” means observable-andreportable and concerns everyday activities used as "prescriptions with which to locate, to identify, to analyze, to classify, to make recognizable, or to find one's way around in comparable occasions" (1984: 2). His interest was in the reflexivity of accounts, particularly the way accounts both report on and are part of what constitutes social life.

Our view on the "power of reflection" has as one of its points of departure the writings of Archer (2007) and her definition of "reflexivity" as "the regular exercise of the mental ability, shared by all normal people, to consider themselves in their (social) contexts and vice versa." (Archer, 2007:4). To Archer, the nature of reflected thought is the holding of "an internal conversation with ourselves inter alia about ourselves" (Archer 2007:73). This conversation involves activities such as "self-observation, self-monitoring, self-criticism, self-evaluation, self-commitment and so forth.” (Archer 2007:72) By answering questions such as “"How do I look?', 'Am I getting this right?', 'Can't you be more exact?', 'Why did you slip up there?' or ‘Could I really do that?'” (Archer 2007:72) we explore ourselves and learn about ourselves in relation to other people. As we can see, Archer employs the term "reflexivity" in a different way than Garfinkel. Archer and Roberts (2009) both focus on reflexivity as a cognitive activity where the self is reflecting on some mental object often connected with the role of the self. In contrast, Garfinkel's use of "reflexivity" refers to the role of reactive action in influencing continued interaction - reactive becomes active and proactive, perhaps mediated by cognitive reflexivity, perhaps not. To avoid confusing the two notions, we are using the term "power of reflection" for the cognitive reflexivity discussed by Archer and Roberts. This capacity is decisive if accountability practices should lead to learning and improvement. However individual differences depending on factors such as age, educational background, and experience are significant for the way in which reflection and accountability come to have a role. Because of these individual differences, care professionals need to be encouraged to 
share their ethical dilemmas and worries with their colleagues. This can be done for example by using critical incidents reports in "a non-blaming way" suggested by Iedema et al, 2006.

\section{Accountability, the ability to communicate and cultural awareness}

The complexity and dynamics of accountability is, as noted earlier, due to its dual relationship to both self and other people. There is a danger of focusing on transparency in accountability situations - both a narcissistic danger leading to excessive self-criticism and a social danger, resulting in total submission to the will of others and their rewards and punishments. An intelligent, and ethical, practice of accountability requires communication with others to get to know both yourself (as an account giver and receiver) and others (as account receivers and givers) to prevent condemnation of yourself or other people. Seeking to inquire into the limits of the accountable self when giving an account, Messner (2009) points to the fact that giving an account requires narrative capacity and is dependent on our ability to use language and communicate. To be successful, this capacity sometimes involves knowing the rules for producing an understandable, acceptable and defendable account.

Demands for accounts often arise when people experience that their expectations are not met. They may ask who is responsible and request explanations from those who are identified as responsible for actions taken or not taken. The role of an account from the account giver's perspective is to defend trust given, or to repair it, if damaged. Communication, in general, presupposes rationality and cooperation from both involved parties (Allwood, 2000), and communication providing an account in particular presupposes sincerity or honesty from the account giver and benevolence from the account recipient (Allwood et al., 2000; Allwood, 2011). 
The distinction between what is considered to be an acceptable account and a defensible one is important. The account recipient may accept the account (e.g., defense of innocence, excuse, justification, and apology, c.f. Schlenker \& Weigold, 1992) for different reasons (incompetence, indifference, self-interest etc.). Thus, acceptance often cannot be the criterion for deciding about the success of an account. An account often also needs to be defensible, i.e., judged against a point of reference outside the relationship between the account giver and the account recipient, e.g. with regard to what is considered rational. For example, after the oil spill accident in the Gulf of Mexico, the accounts from the former CEO of British Petroleum (BP), Tony Hayward, seemed from the beginning to be accepted by the company board. Later, however, Hayward's account was not viewed as defensible because of the reactions from the general public and other stakeholders and, Tony Hayward had to resign. This illustrates the need of asking relevant questions, doing so before judging, and to be prepared to sanction inappropriate behavior.

\section{Implications for empirical studies within health care - Why is accountability relevant for PCC?}

Let us now continue our discussion of how accountability relates to health care - in particular, to PCC. We start by considering the question "Is accountability relevant to PCC?"

The general answer to this question is affirmative since accountability, in fact, is one of the means making PCC possible. Accountability is involved from the beginning to the end in a PCC process. Accountability is involved at the moment when a patient contacts health care. The patient then, either due to having been asked or on his/her own accord, gives an account of why he or she is seeking care. Thus, the patient is being held accountable, by the health professionals, to give an account in which adequate reasons and motives for seeking care are given. An important part of the health professional's job in receiving this account consists of being aware that the patient's account usually involves bodily features, extending beyond its 
vocal verbal or written parts. A trained health professional must always, besides reading status reports and listening to what the patient says, observe, and interpret the patient's behavior and bodily state. Thus, a patient's account for seeking help and behavior in seeking help is partly multimodal. This is of significant relevance for the care and treatment of e.g. patients who are unconscious or suffer from severe dementia. In these cases it is impossible to ask the patient to account for his/her situation and it is most certainly difficult to involve the patient in shared decision making. Also in situations where the person seeking care is not autonomous, care professionals need to recognize this and be concerned about not allocating responsibilities for self-management which undermine the person's self-trust, self-respect etc. (Entwistle \& Watt, 2013). In such situations facial expressions, gestures, body posture, and touch may help in understanding the patient's needs and wants. This requires care professionals to have knowledge of how to observe and interpret this type of communication.

Further, a PCC approach must build on mutual accountability since shared decision-making requires reciprocal information about what to expect from the health care system and professionals in terms of assumption of responsibility by doctors and nurses. In a similar way, patients need to know that they themselves have to assume responsibility to take necessary actions in order to recover or improve their health. Both parties are responsible for developing a health-plan built on the patient's resources, motivation and goals that is possible for both parties to follow and where both parties can hold the other party accountable. The communication needed to agree on a shared decision is delicate (c.f. Roter, 2011; Mahjoub \& Rutledge, 2011; Ha et al., 2010; Joosten et al., 2008) and demands from the professionals that they be able to identify subtle hints from patients as well as interpret understatements and exaggerations. This is especially relevant in the professionals' communication with patients from cultures where people do not want or do not dare to show illness. This also applies in cultures where illness on the contrary is dramatized. 
However, accountability does not only play a role in the relationship between health care seekers and health care givers. It also plays an important role between different types of health care givers, between assistants, nurses, and doctors. Again, the accounts given are not limited to verbal aspects. Also here, facial gestures and tone of voice may influence message content.

Accounts further play a role between persons in the health care administrative hierarchy and between health care administration and external interests. Everywhere, people with relevant insight, usually combined with responsibility, have to give accounts to persons who also require insight since they often have superordinate responsibilities. Giving, receiving, interpreting, and acting on the basis of accounts are a sine qua non of health care, especially of PCC, because there the person's own account of needing help and care is supposed to be given special weight.

An important feature of many of these accounts is, as we have observed, that they are multimodal, i.e., involve understanding information given in several sensory modalities. Thus, if we want to study account giving as well as account reception and interpretation in more detail, certain methods of investigation are more appropriate than others. What is most appropriate is direct observation, combined with video recording. This approach is really the only way to combine the capture of multimodal features with a possibility for careful analysis. Indirect observation, without recording, never permits as careful an analysis as is possible if direct recordings of accountability processes are made. The reason for this is that using interviews or questionnaires, in fact, means getting accounts of accounts, thus introducing the problem of various types of bias, resulting in a problematic relation to actual accounting behavior. 
"The general concern behind calls for person-centered care is an ethical one" (Entwistle \& Watt, 2013:1). However, what is ethical in PCC is contested depending on the perspective; the patient's, the care professional's or the health care system's and the view on justice. We conclude that an ethical understanding of health care accountability, especially those related to PCC, demands awareness of all elements proposed within our model and that accountability should be practiced with good judgment. Whether the change of accountability practices associated with the implementation of PCC will be of this type or not, is in need of further investigations.

Acknowledgment: This work was partially supported by Centre for Person-Centred Care at University of Gothenburg (GPCC), Sweden. GPCC is funded by the Swedish Government's grant for Strategic Research Areas, Care Sciences [Application to Swedish Research Council nr 2009-1088] and co-funded by University of Gothenburg, Sweden and The Health \& Medical Care Committee of the Regional Executive Board, Region Västra Götaland. It was also partially supported by the NOMCO project funded by the NORDCORP program, Joint Committee for Nordic Research Councils for the Humanities and the Social Sciences as well as by the department of Applied IT at the University of Gothenburg.

\section{References}

Allwood, J. (2000), 'An Activity Based Approach to Pragmatics', in H. Bunt and B. Black (eds.), Abduction, Belief and Context in Dialogue: Studies in Computational Pragmatics, Amsterdam: John Benjamins, pp.47-80.

Allwood, J. (2003), 'Meaning Potential and Context. Some Consequences for the Analysis of Variation in Meaning', in H. Cuyckens, R. Dirven and J.R. Taylor (eds.), Cognitive Approaches to Lexical Semantics, Berlin: Moulton de Gruyter, pp. 29-65. 
Allwood, J. (2011), 'Trust as an epistemic, emotional and social simplifier and facilitator', SCCIIL Interdisciplinary Centre, University of Gothenburg.

Allwood, J. and Gunnarsson, M. (2003), 'Bildning - en begreppsanalys', Gothenburg Papers in Theoretical Linguistics S29. Göteborg University, Dept of Linguistics.

Allwood, J., Traum, D. and Jokinen, K. (2000), 'Cooperation, dialogue and ethics'. International Journal of Human-Computer Studies, 53, pp. 871-914.

Archer, M.S. (2007), Making our Way through the World. Human Reflexivity and Social Mobility, Cambridge: Cambridge University Press.

Baldvinsdottir, G. and Johansson, I-L. (2006), 'Förtroende som illusion - skärpt reglering av revision?', in I-L Johansson, S. Jönsson and R. Solli, R. (eds.), Värdet av Förtroende, Lund: Studentlitteratur, pp. 245-268.

Bovens, M. (2007), 'Analysing and Assessing Accountability: A Conceptual Framework', European Law Journal, 13: 4, pp. 447-468.

Committee on Quality of Health Care in America, Institute of Medicine. (2001), 'A new health system for the 21* century', in Committee on Quality of Health Care in America, Institute of Medicine, Crossing the quality chasm: a new health system for the $21^{\text {t }}$ century (pp. 23-38), Washington, D.C.: National Academies Press.

Dellve, L. and Wikström, E. (2009), 'Managing complex workplace stress in health care organizations: leaders' perceived legitimacy conflicts', Journal of Nursing Management, 17, pp. 931-941.

Ekman, I., Swedberg, K., Taft C., Lindseth, A., Norberg A., Brink, E., Carlsson J., DahlinIvanoff, S., Johansson, IL., Kjellgren, K., Lidén, E., Ohlén, J., Olsson, LE., Rosén, H., Rydmark, M. and Sunnerhagen, K.S. (2011), 'Person-centered care - Ready for prime time', European Journal of Cardiovascular Nursing, 10: 4, pp. 248-251. 
Entwistle, V. A. and Watt, I. S. (2013), 'Treating patients as persons: A capabilities approach to support delivery of person-centered care', The American journal of Bioethics, 13: 8, pp. 29-39.

Evetts, J. (2013), 'Professionalism: Value and ideology', Current Sociology, 61: 5-6, pp. 778796.

Foucault, M. (1979), Discipline and punish: the birth of the prison. Harmondsworth: Penguin. Freeman, A.R., McWilliam, C.L., MacKinnon, J.R., DeLuca, S. and Rappolt, S.G. (2009), 'Health professionals' enactment of their accountability obligations: Doing the best they can', Social Science \& Medicine, 69, pp. 1063-1071.

Garfinkel, H. (1984), Studies in Ethnomethodology, Cambridge: Polity Press.

Ha, J.F., Anat, D.S. and Longnecker, N. (2010), 'Doctor-Patient communication: A review', The Ochsner Journal, 10: 1, pp. 38-43.

Hor, S., Iedema, R., Williams, K., White, L., Kennedy, P. and Day, A.S. (2010), 'Multiple Accountabilities in Incident Reporting and Management', Qualitative Health Research, 20, pp. 1091-1100.

Hoskin, K. W. and Macve, R. H. (1986), 'Accounting and the examination: A genealogy of disciplinary power', Accounting, Organization and Society, 11: 2, pp. 105-136.

Hoskin, K. W. and Macve, R. H. (1994), 'Writing, examining, disciplining: the genesis of accounting's modern power', in: A. G. Hopwood and P. Miller (Eds.), Accounting as social and institutional practice. Cambridge, UK: Cambridge University Press, pp. 6797.

Iedema, R., Flabouris, A., Grant, S. and Jorm, C. (2006), 'Narrativizing errors of care: Critical incident reporting in clinical practice', Social Science \& Medicine, 62, pp. 134-144.

Johansson, I-L., Norén, L. and Wikström, E. (2010), 'Patient-centred care: the Nordic position (Guest editorial)', International Journal of Public Sector Management, 23: 4, pp. 325-330. 
Jones, T.C. and Dugdale, D. (2001), 'The concept of an accounting regime', Critical Perspectives on Accounting, 12: 1, pp. 35-63.

Joosten, E.A.G., DeFuentes_Merillas, L., de Weert, G.H., Sensky, T., ven der Staak, C.P.F. and de Jong, C.A.J. (2008), 'Systematic Review of the Effects of Shared DecisionMaking on Patient Satisfaction, Treatment Adherence and Health Status', Psychotherapy and Psychosomatics, 77, pp. 219-226.

Jordan, S., Messner, M. and Becker, A. (2009), 'Reflection and Mindfulness in Organizations: Rationales and Possibilities for Integration', Management Learning, 40, pp. 465-473. Keevers, L. and Treleaven, L. (2011), 'Organizing practices of reflection: A practice-based study', Management Learning, 42: 5, pp. 505-520.

Kukla, R. (2005), 'Conscientious autonomy: Displacing decisions in health care', The Hastings Center Report; 35: 2, pp. 34-44.

Kukla, R. (2007), 'How do patients know?', The Hastings Center Report, 37: 5, pp. 27-35. Laughlin, R. (2007), 'Critical reflections on research approaches, accounting regulation and the regulation of accounting', The British Accounting Review, 39, pp. 271-289.

Levinas, E. (1991), Otherwise than being or beyond essence. Dordrecht: Kluwer Academic Publishers.

Mahjoub, R. and Rutledge, D.N. (2011), 'Perceptions of informed consent for care practices: hospitalized patients and nurses', Applied Nursing Research, 24, pp. 276-280.

Messner, M. (2009), 'The limits of accountability', Accounting, Organizations and Society, 34, pp. 918-938.

Miller, P. and O’Leary, T. (1987), 'Accounting and the construction of the governable person', Accounting, Organization and Society, 12: 3, pp. 235-265.

Mulgan, R. (2000), “Accountability’: an ever-expanding concept?’, Public Administration, 78: 3 , pp. 555-573. 
Ocloo, J. E. (2010), 'Harmed patients gaining voice: Challenging dominant perspectives in the construction of medical harm and patient safety reforms', Social Science \& Medicine, 71, pp. 510-516.

Olsson, L-E., Jakobsson Ung, E., Swedberg, K. and Ekman, I. (2012), 'Efficacy of personcentred care as an intervention in controlled trials - a systematic review', Journal of Clinical Nursing, 22: 3-4, pp. 456-465.

Oudshoorn, N. (2009), 'Physical and digital proximity: emerging ways of health care in faceto-face and telemonitoring of heart-failure patients', Sociology of Health \& Illness, 31: 3, pp. 390-405.

Potter, P. and J. R. Mueller, (2007), 'How well do you know your patients?' Nursing Management, 38: 2, pp. 40-48.

Radovic, S. (2009), 'Om begreppet tillräknelighet', in S. Radovic and H. Anckarsäter (Eds.), Tillräknelighet, Lund: Studentlitteratur, pp. 17-50.

Roberts, J. (2001), 'Corporate governance and the ethics of narcissus', Business Ethics Quarterly, 11: 1, pp. 109-125.

Roberts, J. (2009), 'No one is perfect: The limits of transparency and an ethic for 'intelligent' accountability', Accounting, Organizations and Society, 34, pp. 957-970.

Rosemond, C.A., Hanson, L.C., Ennet, S.T., Schenk, A.P. and Weiner, B.J. (2012), 'Implementing person-centered care in nursing homes', Health Care Management Review, 37: 3, pp. 257-266.

Roter, D.L. (2011), 'Oral literacy demand of health care communication: Challenges and solutions', Nurs Outlook, 59, pp. 79-84.

Schlenker, B.R. and Weigold, M.F. (1992), 'Interpersonal processes involving impression regulation and management', Annual Review of Psychology, 43, pp. 133-168.

Sinclair, A. (1995), 'The chameleon of accountability: forms and discourses', Accounting, Organization and Society, 20: 2-3, pp. 219-237. 
van Woerkum, C. and Aarts, N. (2012), 'Accountability: New challenges, new forms', Journal of Organizational Transformation \& Social Change, 9: 3, pp. 271-283.

Walker, S.P. and Llewellyn, S. (2000), 'Accounting at home: some interdisciplinary perspectives', Accounting, Auditing \& Accountability Journal, 13: 4, pp. 425-449.

Wirtz, V., Cribb, A. and Barber, N. (2006), 'Patient-doctor decision-making about treatment within the consultation - A critical analysis of models', Social Science \& Medicine, 62, pp. 116-124. 


\section{Diagram, Table and Figure captions}

Diagram 1. The Morphological structure of - accountability.

Table 1. Semantic roles involved in "giving an account", "being accountable" and "being held accountable for".

Figure 1. Box 1. Accountability as a Social Relation.

\section{Diagram, Table and Figure}

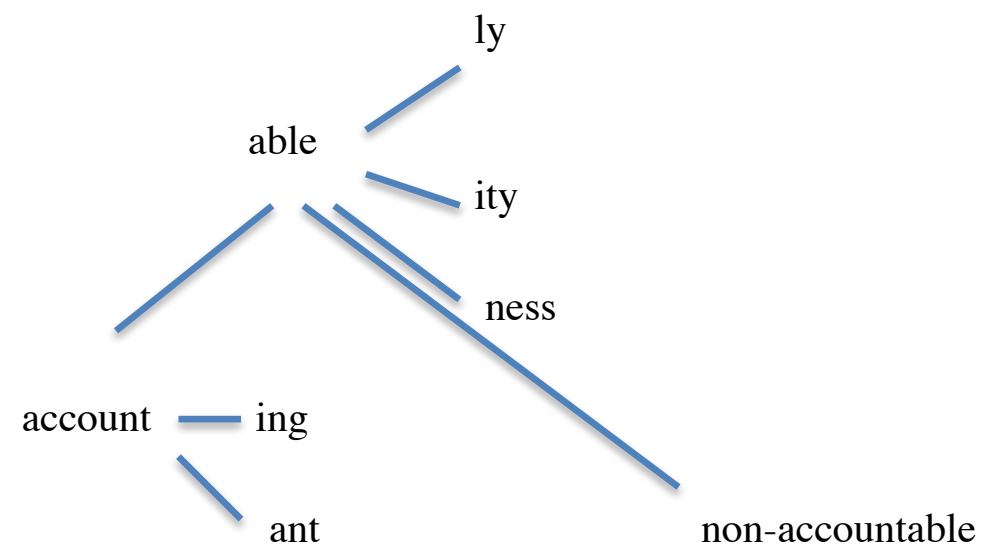

Diagram 1. The Morphological structure of - accountability. The length of the branches has no significance except for exposing what morphemes are involved.

\begin{tabular}{|c|c|c|c|c|c|c|}
\hline Agent & $\begin{array}{l}\text { Action } \\
\text { /relation }\end{array}$ & $\begin{array}{l}\text { Object } \\
\text { Purpose }\end{array}$ & Patient & $\begin{array}{l}\text { Instrument } \\
\text { Purpose } \\
\text { Result }\end{array}$ & $\begin{array}{l}\text { Time } \\
\text { Place }\end{array}$ & $\begin{array}{l}\text { Bene- } \\
\text { factor } \\
\text { Action } 3\end{array}$ \\
\hline$X$ & $\begin{array}{l}\text { accounts } \\
\text { for (action 2) }\end{array}$ & $\mathrm{Y}$ & to $\mathrm{Z}$ & $\begin{array}{l}\text { Using } \\
\text { Instrument I, } \\
\text { with purpose } \\
\mathrm{P}, \text { result } \mathrm{R}\end{array}$ & $\begin{array}{l}\text { At time } \\
t \text { and } \\
\text { place } p\end{array}$ & \\
\hline$X$ & $\begin{array}{l}\text { Is accountable } \\
\text { for }\end{array}$ & $\mathrm{Y}$ & to $\mathrm{Z}$ & $\begin{array}{l}\text { Using } \\
\text { Instrument I, } \\
\text { with purpose } \\
\mathrm{P} \text {, result R }\end{array}$ & $\begin{array}{l}\text { At time } \\
\mathrm{t} \text { and } \\
\text { place } \mathrm{p}\end{array}$ & \\
\hline$X$ & $\begin{array}{l}\text { Is held } \\
\text { accountable } \\
\text { for } \\
\text { (action 3) }\end{array}$ & $\mathrm{Y}$ & to $\mathrm{Z}$ & $\begin{array}{l}\text { Using } \\
\text { Instrument I, } \\
\text { with purpose } \\
\mathrm{P}, \text { result } \mathrm{R}\end{array}$ & $\begin{array}{l}\text { At time } \\
\mathrm{t} \text { and } \\
\text { place } \mathrm{p}\end{array}$ & by $\mathrm{W}$ \\
\hline
\end{tabular}

Table 1. Semantic roles involved in "giving an account", "being accountable" and "being held accountable for". 
A relationship qualifies as a case of accountability when:

1. there is a relationship between an actor and a forum

2 . in which the actor is obliged

3. to explain and justify

4. his conduct;

5. the forum can pose questions;

6. pass judgement;

7. and the actor may face consequences.

Figure 1. Box 1. Accountability as a Social Relation (Bovens 2007:452). 